\title{
Biology of Obesity: Lessons from Animal Models of Obesity
}

\author{
Keizo Kanasaki and Daisuke Koya \\ Division of Diabetes \& Endocrinology, Kanazawa Medical University, Uchinada, Ishikawa 920-0293, Japan \\ Correspondence should be addressed to Daisuke Koya, koya0516@kanazawa-med.ac.jp
}

Received 14 September 2010; Accepted 13 December 2010

Academic Editor: Monica Fedele

Copyright ( $\odot 2011$ K. Kanasaki and D. Koya. This is an open access article distributed under the Creative Commons Attribution License, which permits unrestricted use, distribution, and reproduction in any medium, provided the original work is properly cited.

\begin{abstract}
Obesity is an epidemic problem in the world and is associated with several health problems, including diabetes, cardiovascular disease, respiratory failure, muscle weakness, and cancer. The precise molecular mechanisms by which obesity induces these health problems are not yet clear. To better understand the pathomechanisms of human disease, good animal models are essential. In this paper, we will analyze animal models of obesity and their use in the research of obesity-associated human health conditions and diseases such as diabetes, cancer, and obstructive sleep apnea syndrome.
\end{abstract}

\section{Introduction}

Obesity, defined as a body mass index (BMI) $>30 \mathrm{~kg} / \mathrm{m}^{2}$, is a significant health problem [1]. Obesity has reached epidemic proportions globally, and the World Health Organization estimates that there are more than 1 billion overweight adults, of which at least 300 million are obese [2]. Societal changes and the worldwide nutrition transition have driven the obesity epidemic over recent decades. Economic growth as well as modernization, urbanization and globalization of food markets are some of the elements that have contributed to the obesity epidemic. Significant shifts toward less physically demanding work have been observed worldwide. Decreased physical activity has also been associated with increasing opportunities to use automated transport, have technology in the home, and engage in more passive leisure pursuits [2].

Obesity is associated with premature death through increasing the risk of many chronic diseases, including type 2 diabetes, cardiovascular disease, and certain cancers (Figure 1) [3, 4]. In addition, obesity is associated with respiratory difficulties, chronic musculoskeletal problems, lumbago, skin problems, and infertility (Figure 1) [4]. Most of the evidence proposing obesity-associated health problems has been obtained from epidemiological analyses of human subjects; the precise molecular mechanisms of obesity-associated health problems have not yet been determined. In this paper, we will summarize reports associated with obesity-related pathology using animal models and also propose further demand for animal research models to address the worldwide obesity epidemic.

\section{Animal Models of Obesity}

There are many rodent and nonrodent models of obesity. We introduce several widely used important animal models of obesity in this section.

\subsection{Rodent Models}

\subsubsection{Monogenic Mouse Obesity}

Lethal Yellow Mutant Mouse $\left(A^{y}\right)$. Among the several commonly existing obese mice currently used in research, the agouti mutation mouse was first reported more than century ago. In 1992, the agouti protein was cloned by Bultman et al., and agouti became the first obesity gene characterized at the molecular level [5]. Agouti is a pigment control gene transiently expressed in follicular melanocytes to induce the production of red/yellow pheomelanin pigment and inhibit black/brown pigment [6-8]. The lethal yellow mutant mouse $\left(A^{y}\right)$ is one of five dominant agouti mutations and has been found to be an excellent mouse model of obesity [5]. The $A^{y}$ mutation is characterized by the deletion of $120-170 \mathrm{~kb}$ genomic DNA, resulting in ubiquitous agouti expression due 


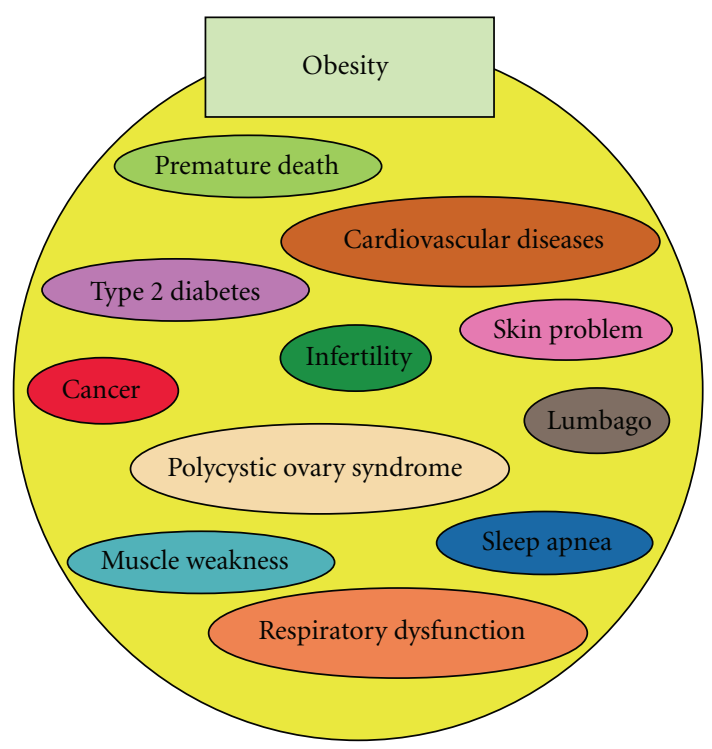

FIGURE 1: Obesity-associated complications. Obesity is associated with various health conditions in humans.

to loss of the tissue-specific control promoter element [911]. $A^{y}$ mice exhibit several phenotypes such as a yellow coat color, mature-onset obesity, type-II diabetes, hyperleptinemia, increased linear growth, higher tumor susceptibility, and infertility [5]. Transgenic mice expressing ubiquitous agouti exhibited yellow coat color, obesity, hyperinsulinemia, and hyperglycemia similar to $A^{y}$ mouse [12], revealing the molecular mechanism of agouti in mouse phenotype. Mice with adipose tissue-specific agouti overexpression exhibit an overgrowth of adipose tissue without alteration of food intake, suggesting that increased fat in this model is due to changes in energy metabolism [13]. The adipose tissue agouti overexpression model could be relevant to human obesity because agouti gene expression is found in human adipose tissue $[14,15]$ and is increased in the adipose tissue of type 2 diabetic subjects [16]. Likely the ectopic expression of agouti in mice pancreas stimulated the release of insulin by pancreatic $\beta$-cells, which may further enhance agoutistimulated lipogenesis [17]. Transgenic Agouti expression in skin did not induce obesity, suggesting that the obesogenic role of agouti is tissue dependent [18].

Leptin Signaling Defects in Mice: ob/ob and db/db Mouse Models. In 1949, researchers from the Jackson Laboratory discovered obese mice by chance [19]. Responsible mutation gene is named as obese (ob) gene. The ob/ob mutation is recessive, and neonatal mutant mice are normal when compared to unaffected control littermates. Mutant mice, however, gain weight rapidly throughout their lives, eventually reaching a weight that is three times that of control mice. The phenotype is clear, but identification of the gene responsible for the obese phenotype took nearly 50 years [20]. In 1994, Zhang et al. identified the mutation in the leptin gene as responsible for ob mutation by positional cloning [20]. Leptin is a gene expressed abundantly in the adipose tissue. Characterization of this mutation revealed a single base pair deletion in the leptin coding region that results in a frame shift and a premature stop codon [20]. The leptin protein plays an important role in appetite control. Therefore, $o b / o b$ mice exhibit uncontrollable food intake, obesity, type 2 diabetes, and insulin resistance with hyperinsulinemia.

The $d b / d b$ mouse was identified initially in 1966 by researchers in the Jackson Laboratory as an obese mouse [21]. The $d b$ (stands for "diabetes") mutation is an autosomal recessive trait that encodes for a G-to-T point mutation in the leptin receptor gene, resulting in defective leptin signaling $[22,23]$. Impaired leptin signaling in the hypothalamus leads to persistent hyperphagia and obesity, with consequent hyperleptinemia, insulin resistance, and increased insulin levels $[22,23]$. At 1 month of age, $d b / d b$ mice are larger/obese when compared to control (heterozygous) littermates, and $d b / d b$ mice present increased fat deposition in the inguinal and axillary regions. $d b / d b$ mice also develop frank hyperglycemia by 8 weeks of age. Consequently, these mice are widely used as a model for the study of type 2 diabetes $[22,23]$.

2.1.2. Polygenic Mouse Obesity. Although monogenic models provide important information on the biology of obesity, human obesity is most likely mediated by multiple genes. Therefore, polygenic models could be much more relevant to human obesity.

New Zealand Obese (NZO) Mouse. The NZO strain is a polygenic mouse model of obesity that exhibits type 2 diabetes only in males. NZO mice increase their body weight rapidly during the first 2 months of life because of hyperphagia that may be associated with leptin resistance, although they have genetically normal leptin and leptin receptors. Among polygenic mouse models of obesity, NZO mice exhibit the most severe phenotype, with fat depots accounting for more than $40 \%$ of total body weight at 6 months of age [24]. Additionally, NZO mice exhibit decreased exercise activity when compared to control or even $o b / o b$ mice [25]. This information suggests that like human obesity, obesity in NZO mice is due to a combination of hyperphagia, reduced energy expenditure, and insufficient physical activity.

Tsumura Suzuki Obese Diabetes (TSOD) Mouse. Through the selection of obese and urine sugar positive colonies from the ddY strain of mice, Tsumura and Suzuki established two inbred strains. The TSOD strain develops obesity with diabetes, whereas the Tsumara Suzuki nonobese (TSNO) strain does not become obese [26]. Male TSOD mice exhibit polygenic obesity with hyperglycemia and hyperinsulinemia $[26,27]$. Although the mean values of fed blood glucose concentrations in TSOD mice are increased with age $(232 \mathrm{mg} / \mathrm{dl}$ at 13 weeks, $269 \mathrm{mg} / \mathrm{dl}$ at 16 weeks, and $346 \mathrm{mg} / \mathrm{dl}$ at 24 weeks), severe diabetes does not develop because TSOD mice display increased $\beta$-cell mass and maintain insulin secretion 
to control blood glucose [26]. Older TSOD mice display similar lesion as diabetic nephropathy and neuropathy [28].

M16 Mouse. The M16 mouse, an outbred mouse model of early-onset polygenic obesity, was developed through longterm selection for 3- to 6-week weight gain in an ICR background [29]. M16 mice exhibit hyperphagia, hyperinsulinemia, and hyperleptinemia compared to ICR controls. M16 males and females were found to be moderately hyperglycemic compared to ICR controls, with $56 \%$ and $22 \%$ higher fasted plasma glucose levels, respectively, at 8 weeks of age [29].

Kuo Kondo (KK) Mouse. The KK mouse is a polygenic model of obesity that also exhibits type 2 diabetes. The KK mouse was developed in Japan with selective inbreeding for large body size [30]. KK mice display hyperphagia, hyperinsulinemia, and insulin resistance and show moderate obesity by 2 months of age [31, 32]. Insulin resistance in KK mice precedes the onset of obesity [33]. The KK mouse strain was modified to develop the KKA $A^{y}$ mouse by transferring the lethal yellow obese gene $\left(A^{y}\right)$; the KK $A^{y}$ mouse is widely used for obesity and diabetes research in the testing of experimental therapies [34].

\subsubsection{Rat Models of Obesity}

Zucker Fatty Rat (ZFR). In 1961, L. M. Zucker and T. F. Zucker reported a seminal finding in obesity research [35]: an autosomal recessive mutation in the fatty $(f a)$ gene on chromosome 5 . These rats are characterized by hyperphagia and early-onset obesity, which appears at 5 weeks of age as an accumulation of subcutaneous fat. Although ZFR also exhibits marked insulin resistance [36], their blood sugar levels remain normal [37]. Later, the $f a$ gene was shown to be the leptin receptor gene [38]. A ZFR does not develop diabetes [37]. However, a substrain of the ZFR that exhibits frank diabetes was discovered and was designated the Zucker diabetic fatty (ZDF) rats [39].

Wistar Fatty Rat. In 1981, Ikeda et al. reported another obesity rat model, the Wistar fatty rat (WFR) [40]. The WFR strain was derived by transferring the $\mathrm{fa}$ gene from ZFR (13 M strain) to Wistar Kyoto rats, which exhibit poor glucose tolerance [40]. WFR displays obesity from 3 weeks after birth and develops obesity-related diseases such as type 2 diabetes, hyperinsulinemia, and hyperlipidemia. Metabolic abnormalities are prominent in WFR males, but not in WFR females, which display only mild insulin resistance and some glucose intolerance [40]. The appearance of diabetes in WFR but not in ZFR, despite the presence of the fa (leptin receptor) mutation in both strains, could be explained by the presence of other genetic factors in WFR. The WFR strain is widely used for research in type 2 diabetes because aged WFR displays diabetic complications such as nephropathy and neuropathy [41-44].

Otsuka Long Evans Tokushima Fatty (OLETF) Rat. OLETF rats, established by Otsuka Pharmaceuticals in Tokushima,
Japan, were developed by the selection of spontaneously type 2 diabetic rats from the outbreeding of Long Evans rats in a closed colony of Charles River [45]. OLETF rats are hyperphagic beginning several weeks after birth, with increasing body weight eventually progressing to frank obesity [46]. At approximately 25 weeks after birth, all male OLETF rats display diabetes, as determined by oral glucose tolerance test, whereas only $30 \%$ of female OLETF rats develop diabetes even after 60 weeks of age. Hyperinsulinemia is observed beginning at 8 weeks of age, and insulin resistance is observed beginning at 12 weeks of age. At 25 weeks of age, male OLETF rats display hyperplasia of pancreatic islets, but islets become atrophic by 60 weeks of age $[46,47]$. In contrast to ZDF rats, hyper-free fatty acidemia has not been observed in OLETF rats. Instead, hypertriglyceridemia is found to precede the onset of hyperglycemia and insulin resistance [47]. OLETF rats are widely used in obesity and diabetes research.

\subsubsection{Diet-Induced Obesity}

High-Fat Diet. A high-fat diet (HFD) is often utilized in obesity research as a non-leptin-deficient model. There are mouse strain-specific differences in responses to the HFD (Table 1) [48]. Among the various strains, C57BL/6J mice are the most widely used for HFD-induced obesity because they exhibit abnormalities similar to human metabolic syndrome when fed the HFD [49]. Interestingly, within the C57 mouse strain, there are significant differences among substrains in response to the HFD. For instance, whereas C57BL/6J mice exhibit HFD-induced obesity, hyperinsulinemia, and insulin resistance that closely parallel the progression of human disease, C57BL/KsJ mice display a weak phenotype [49]. Beside C57BL/J6 mice, sand mice and spiny mice are also used in obesity/type 2 diabetes research. Sprague Dawley or Long Evans rats are also used for nonmouse rodent models of HFD-induced obesity [50].

Using such high-fat diet-induced obesity mice models, some clues to fight against human obesity have been reported; manipulation of diet may rescue the obesity phenotype even in high-fat-fed condition.

Watanabe et al. reported seminal finding about the antiobesitogenic role of bile acids (BAs) in mice. BAs have been long recognized as simple lipid solubilizers, however, during the last decades researchers revealed that BAs play pivotal roles in the complex metabolic regulations. Watanabe et al. found that high-fat diet supplemented with $0.5 \%$ cholic acid, the BA found in the largest amount, prevented weight gain and adiposity without alteration in the amount of food intake [51]. They found that BAs activate G-proteincoupledTGR5 receptor and induce type 2 deiodinase activity. Such activation of type 2 deiodinase results in the conversion of thyroxine (T4) to triiodothyronine (T3), which enhances energy expenditure [51]. Furthermore, agonistic compound for TGR5, INT-777, mimics such metabolic effect of BAs and inhibited the onset of steatosis in high-fat-fed mice [52]. Furthermore, INT-777 induces incretin effects via the secretion of glucagon-like peptide (GLP)-1 and therefore ameliorated glucose tolerance [52]. These researches revealed 
the potential importance of BAs for the prevention of dietinduced obesity and associated health problem. Interestingly postcholecystectomized patients have been shown to have high prevalence of type 2 diabetes [53].

Another nutritional intervention method, which could prevent metabolic abnormality, is the diet with high ketogenic essential amino acid (KAA) such as leucine, isoleucine, valine, lysine, and threonine. Zhang et al. have reported that high-leucine feeding in mice prevented high-fat dietinduced obesity [54]. Such enhanced administration of highKAA mixture diet modulated lipid synthetic pathway and prevented hepatic steatosis and insulin resistance with the reduction of body weight under the high-fat diet [55]. Interestingly such high-KAA mixture has been shown to improve insulin sensitivity in elderly type 2 diabetic subjects [56]. These reports indicated that the high-fat diet-induced obesity animals could be the good model for the experimental therapy and the translational research to discover a novel therapeutic strategy for obesity epidemic.

\subsection{Nonrodent Models of Obesity}

Obese Monkeys. During evolution, primates diverged from rodent lineages about 65-85 million years ago [57]. In comparison, humans and other great apes (Hominoidea) diverged from Old World monkeys (Cercopithecoidea) a relatively recent 25 million years ago [58]. Obesity models in Old World monkeys, such as macaques, rhesus monkey, and baboons, would therefore provide information relevant to human obesity. When raised in indoor cages, Rhesus monkeys exhibit increased rates of obesity, with some of them developing obesity-associated diseases [5961]. Captive macaques display obesity in an age-dependent manner when given food ad libitum [62]. Like humans, these monkeys develop type 2 diabetes and diabetic complications. It is likely that reduced exercise increases the risk of obesity in these monkeys [62-64]. Spontaneous obesity is also found in wild baboons and in a pedigreed colony [65-67] and occurs in free-ranging rhesus monkeys [68]. Furthermore, a species of Japanese monkey, Macaca fuscata, develops obesity without frank diabetes [69].

\section{Human Disease and Obesity Animal Models}

Genetic models provide useful information about the biology of obesity in humans. This does not mean, however, that these models can provide information on how obesity can cause other health problems. In this section, we introduce several animal models for analyzing human obesityassociated disease pathology.

3.1. Diabetes and Obesity. Type 2 diabetes is associated with insulin resistance and is one of the most common metabolic diseases. The incidence of type 2 diabetes has dramatically increased in the past two decades, coinciding with the epidemic of obesity. The pathogenesis of insulin resistance and diabetes-associated complications remains unclear. Research on type 2 diabetes using animal models of obesity is therefore quite significant.
Models of obesity with type 2 diabetes are classified into two categories: (1) those containing a mutation in the leptin or leptin receptor gene and (2) polygenic models. Obese rodents, such as Zucker rats, $o b / o b$ mice, and $d b / d b$ mice, are used as models for type 2 diabetes. Obesity in these models is due to leptin signaling deficiency. These rodent models exhibit microvascular complications similar to humans, such as diabetic retinopathy and nephropathy, and provide important models for testing experimental therapeutics. However, leptin abnormalities only comprise a minority of obesity/diabetes cases in humans [70-72] and are not the same condition of type 2 diabetes that is a worldwide epidemic.

Polygenic models of obesity with diabetes may provide more insight to the human condition. Certain inbred strains of mice exhibit remarkable obesity when fed on HFD, whereas others remain lean $[48,49,73]$, suggesting genediet interactions. Furthermore, some of the strains exhibit obesity with severe insulin resistance and glucose intolerance, whereas others are highly sensitive to insulin-mediated glucose uptake and are resistant to the onset of diabetes (Table 1) $[50,74,75]$. In contrast, some strains are very prone to type 2 diabetes but not severely obese. Those polygenic models allow for analysis of diabetic phenotypes alone, or the mice can be fed on HFD or crossed with another obesity mouse model, such as $o b / o b, d b / d b$, or $A^{y}$ (Table 1) [50, 74, 75].

3.2. Cancer and Obesity. Obesity in humans is associated with the incidence of several cancers. Likewise, type 2 diabetes has been associated with an increased risk of cancer. Several mechanisms have been proposed to explain the interaction between obesity and cancer development, including the prevalence of type 2 diabetes, increased insulin resistance, elevated levels of insulin-like growth factor 1 (IGF-1), and increased production of sex steroid hormones and adipocytokines [76-80]. However, clear molecular mechanisms that explain obesity-associated cancer have yet to be determined. Recently, Park et al. reported a breakthrough observation in carcinogenesis in obesity [81]. They found that diethylnitrosamine-induced HCC is significantly higher in both genetically $(o b / o b)$ and HFD-induced (59\% fat, 15\% protein, 26\% carbohydrates) obese mice [81]. Furthermore, HFD induced the growth of subcutaneously injected HCC, suggesting that obesity has a systemic effect on tumorigenesis [81]. With regard to the mechanisms of tumorigenesis in obesity, they found that obesity is associated with increased intracellular transcriptional factor STAT signaling and liver inflammation [81]. This inflammation was demonstrated to be essential for the tumor promoting effects of obesity because the depletion of signaling by inflammatory cytokines IL- 6 and TNF- $\alpha$ abolished the tumor promoting effects of obesity [81].

Metformin belongs to the biguanide class of antitype 2 diabetic drugs. Since the middle ages, the biguanide Galega officinalis (goat's rue or French lilac) has been used to treat diabetic patients. Accumulating evidence suggests that metformin reduces cancer incidence in type 2 diabetic patients. Metformin activates AMPK and inhibits the 
TABLE 1: Different phenotypes of inbred mouse strains with diet- or genetically induced obesity (summary of references $[50,74,75]$ ).

\begin{tabular}{|c|c|c|}
\hline Strain & Characteristics & Crossed with obese mice, and so forth \\
\hline $\mathrm{C} 57 \mathrm{BL} / 6 \mathrm{~J}$ & High-fat diet-induced diabetes and obesity [119] & Lep $^{o b / o b}$ mice exhibit obesity but not diabetes [120] \\
\hline C57BLKS/J & $\begin{array}{l}\text { High-fat diet-induced diabetes and obesity weaker than } \\
\text { C57BL/6J [49] }\end{array}$ & Lep $^{o b / o b}$ mice exhibit obesity with severe diabetes $[120]$ \\
\hline $\mathrm{DBA} / 2$ & $\begin{array}{l}\text { More glucose tolerance than C57BL/6 on a high-fat diet } \\
{[121]}\end{array}$ & Lep $^{o b / o b}$ mice exhibit obesity with severe diabetes [122] \\
\hline $129 \mathrm{sv}$ & $\begin{array}{l}\text { Low insulin; more glucose tolerance than other strains on a } \\
\text { high-fat diet [123] }\end{array}$ & $\begin{array}{l}\text { Homozygous for db allele } d b^{3 J} \text { mice display } \\
\text { mild/transient hyperglycemia with marked } \\
\text { hyperinsulinemia and develop hypoglycemia leading to } \\
\text { sudden death [124] }\end{array}$ \\
\hline BTBR & $\begin{array}{l}\text { Abdominal obesity with peripheral, but not hepatic insulin } \\
\text { resistance [125] }\end{array}$ & Lep $^{o b / o b}$ mice exhibit obesity with severe diabetes [126] \\
\hline $\mathrm{A} / \mathrm{J}$ & $\begin{array}{l}\text { Low glucose level even on a high-fat diet; obesity and } \\
\text { diabetes-resistant }[119,127,128]\end{array}$ & Not reported \\
\hline $\mathrm{BALB} / \mathrm{c}$ & Similar to A/J; glucose tolerance [121] & $\begin{array}{l}\text { Lep }^{o b / o b} \text { mice exhibit reduced adiposity and increased } \\
\text { thermogenesis and are fertile [129] }\end{array}$ \\
\hline $\mathrm{C} 3 \mathrm{H}$ & High glucose tolerance with robust insulin secretion [121] & Not reported \\
\hline AKR & $\begin{array}{l}\text { Sensitive to diet-induced obesity with hyperinsulinemia and } \\
\text { insulin resistance [48] }\end{array}$ & Not reported \\
\hline CAST/Ei & Lean at 12 weeks on a high-fat diet [130] & Not reported \\
\hline Nonobese Diabetic & $\begin{array}{l}45 \% \text { fat diet-induced transient hyperglycemia with severe } \\
\text { obesity [75] }\end{array}$ & Not reported \\
\hline New Zealand Obese & $\begin{array}{l}\text { Resemble metabolic syndrome in humans; high-fat } \\
\text { diet-induced obesity and hyperglycemia }[24,25]\end{array}$ & Not reported \\
\hline FVB & $\begin{array}{l}\text { High glucose levels with lower levels of insulin on normal } \\
\text { chow [75] }\end{array}$ & $\begin{array}{l}\text { Lepr }^{d b / d b} \text { mice display insulin resistance, severe } \\
\text { hyperglycemia, and marked hyperinsulinemia } \\
\text { compared to C57BL/6 [131] }\end{array}$ \\
\hline Kuo Kondo & $\begin{array}{l}\text { Obesity; hyperleptinemia; increased glucose and HbAlc; } \\
\text { hyperinsulinemia similar to C57BLKS/J Lepr }{ }^{d b / d b} \text { mice [30] }\end{array}$ & $\begin{array}{l}A^{y} \text { mutation in agouti results in frank diabetes with } \\
\text { nephropathy [34] }\end{array}$ \\
\hline TallyHo & Natural model of obesity with type 2 diabetes [132] & Not reported \\
\hline $\begin{array}{l}\text { Nagoya-Shibata- } \\
\text { Yasuda }\end{array}$ & $\begin{array}{l}\text { Exhibit obesity; all males and } 1 / 3 \text { of females exhibit glucose } \\
\text { intolerance [133] }\end{array}$ & Not reported \\
\hline ALS/Lt & Sensitive to alloxan-induced diabetes [134] & $\begin{array}{l}\text { Introduction of } A^{y} \text { mutation induces diabetes in } 100 \% \\
\text { of males and } 60 \% \text { of females at } 24 \text { weeks of age [135] }\end{array}$ \\
\hline M16 & $\begin{array}{l}\text { Increased body weight, fat and food intake; both males and } \\
\text { females develop hyperinsulinemia; only males develop } \\
\text { moderate hyperglycemia [29] }\end{array}$ & Not reported \\
\hline LG and SM & $\begin{array}{l}\text { High-fat diet-stimulated body weight gain and increased } \\
\text { plasma glucose more in SM than LG mice [136] }\end{array}$ & Not reported \\
\hline $\begin{array}{l}\text { Tsumura, Suzuki, } \\
\text { Obese Diabetes }\end{array}$ & Obesity and moderate diabetes $[26,27]$ & Not reported \\
\hline Akita & Mutation in insulin 2 gene; nonobese [137] & Not reported \\
\hline
\end{tabular}

mTOR signaling pathway via various mechanisms [8286]. Metformin treatment has been shown to result in a gene expression profile similar to that of long-term caloric restriction [87], which can reduce the incidence of many age-related diseases, including cancer [88, 89]. Metformin treatment inhibits high-energy diet-stimulated colon cancer cell growth [90] and breast tumor growth in HFD-fed mice but did not inhibit tumor growth in mice fed normal chow [91]. Although the effects of metformin in obesity-related cancer biology are not clear, these reports suggest that the tumor suppressive effect of metformin may involve the amelioration of a systemic metabolic profile associated with a high-energy diet and obesity.

Elevated leptin levels, often found in obesity, may affect cancer cell growth. Recently, Ribeiro et al. injected androgeninsensitive murine prostate carcinoma RM1 cells into control male C57BL6 and genetic (ob/ob mice and $d b / d b$ mice) and HFD mouse models of obesity [92]. They found that low-leptin models ( $o b / o b$ and HFD mice) exhibited large tumors, whereas high-leptin $(d b / d b)$ mice exhibited small tumors, suggesting that leptin may inhibit RM1 tumor growth [92]. In contrast, Gonzalez et al. reported that leptin 
may accelerate the growth of breast tumors in mice via induction of VEGF-VEGFR2-mediated angiogenesis [93], although their study used immunodeficient SCID mice and not a mouse model of obesity [94]. Similar leptininduced proliferation and invasiveness has been shown in endometrial cancer [95]. Bartucci et al. reported that colorectal cancer stem cells express leptin receptors, and therefore leptin may induce tumor growth and interfere with the cytotoxic effects of the anticancer drug 5-FU [96]. The reports regarding the role of leptin in carcinogenesis are still very controversial and require further followup studies.

3.3. Obstructive Sleep Apnea and Obesity. Obstructive sleep apnea (OSA) is an important obesity-associated health problem that is characterized by obstruction of the airway and depletion of oxygen tone in the blood. OSA may be associated with the onset of hypertension, diabetes, and coronary heart disease. Although OSA is of clinical importance, the etiology of OSA is not yet clear, perhaps due to the lack of appropriate animal models. The first animal model reported to exhibit sleep apnea was the English bulldog [97]. These animals exhibit respiration disorders and decreased $\mathrm{O}_{2}$ saturation that worsen during rapid-eyemovement sleep. Most bulldogs experience less than 90\% $\mathrm{O}_{2}$ saturation for prolonged durations [97]. Two varieties of obese pigs were also found to be good models of OSA $[98,99]$. Although these models provide important information about the pathomechanisms of OSA, largeanimal-based research is technically difficult. Therefore, for the development of experimental therapies and drugs, rodent models are superior. In 1996, Van Lunteren et al. reported altered respiratory-associated muscle contraction in genetically obese ZFR [100]. Later, this model was found to exhibit sleep apnea syndrome [101]. ZFRs have since been used for various experimental therapies and have provided important information about OSA [102-104].

Although these dog, pig, and rat models help improve our understanding of the pathophysiology of OSA, mouse models are critical in identifying the genes conferring disease risk [105]. Tagaito et al. developed a gas-delivery system that alters $\mathrm{O}_{2}$ levels depending on the sleep-wake status of C57BL/6 male mice. However, this model is not a natural OSA model and is not a good representation of OSA [106]. Recently, NZO mice were used as a model mouse for sleep apnea syndrome [107]. NZO mice exhibit polygenic obesity and metabolic syndromes, such as insulin resistance, diabetes, hyperlipidemia, and hypertension (Table 1), much like a human sleep apnea patient. This report suggests that the NZO mouse may be a useful model for testing new drugs and experimental therapies for OSA.

\section{Why Do Humans Gain Weight? Why Do Humans Like to Eat Fat?}

All the data above might be focused mainly on the pathogenesis of obesity/obesity-related complications. Most publications may shed light on the pathology of obesity by forcing HFD or genetic mutations in rodents; however, the conditions are very different from the real problems that humans are facing. For example, although leptin-deficient rodents have been used in many obesity-associated studies, leptin/leptin receptor mutations are rare in humans [70-72]. The main difference between experimental animal models and human obesity is that humans do not have induced gene mutations and are not forced to eat HFDs. Instead, humans tend to enjoy eating such diets. If we can answer the question of why some individuals prefer to eat high-fat food and others do not, we would have a direct solution for obesity. Little evidence is currently available on this topic, but some seminal results have been shown [108, 109]. It has also been reported that the variation in fat consumption (ranging from 26 to $83 \%$ of total energy) is dependent on the response of inbred mouse strains to the macronutrient diet selection paradigm [110]. This theory suggests that there are strainspecific differences in food selection behavior, which could potentially be mediated by differences in brain neuropeptides [111-116]. These reports indicate that further investigation on this topic in conjunction with human epidemiological and genetic studies is required.

\section{Conclusion}

We have summarized many current animal models of obesity and obesity-associated human diseases. However, animal models have not yet been established for some devastating obesity-associated human diseases, including polycystic ovary syndrome $[117,118]$, which is extremely prevalent and constitutes one of the most common endocrinopathy in women of reproductive age. Suitable animal models are fundamental to testing novel therapeutic strategies against disease. Therefore, intensive and continuous efforts should be made to establish novel obesity-associated animal models that mimic human health problems.

\section{Acknowledgments}

The authors declare no conflict of interest. Author's laboratory is supported by the grant from Japan Society for the Promotion of Science to D. Koya and a grant from the Uehara Memorial Foundation to D. Koya. K. Kanasaki is currently supported by a grant from Kanae Foundation for the Promotion of Medical Science.

\section{References}

[1] P. Kopelman, "Health risks associated with overweight and obesity," Obesity Reviews, vol. 8, no. 1, pp. 13-17, 2007.

[2] World Health Organization, "Fact sheet: Obesity and overweight," http://www.who.int/hpr/gs.fs.obesity.shtml.

[3] D. P. Guh, W. Zhang, N. Bansback, Z. Amarsi, C. L. Birmingham, and A. H. Anis, "The incidence of co-morbidities related to obesity and overweight: a systematic review and meta-analysis," BMC Public Health, vol. 9, article 88, 2009.

[4] W. V. Brown, K. Fujioka, P. W. Wilson, and K. A. Woodworth, "Obesity: why be concerned?" The American Journal of Medicine, vol. 122, no. 4, pp. S4-S11, 2009. 
[5] S. J. Bultman, E. J. Michaud, and R. P. Woychik, "Molecular characterization of the mouse agouti locus," Cell, vol. 71, no. 7, pp. 1195-1204, 1992.

[6] D. Lu, D. Willard, I. R. Patel et al., "Agouti protein is an antagonist of the melanocyte-stimulating-hormone receptor," Nature, vol. 371, no. 6500, pp. 799-802, 1994.

[7] S. E. Millar, M. W. Miller, M. E. Stevens, and G. S. Barsh, "Expression and transgenic studies of the mouse agouti gene provide insight into the mechanisms by which mammalian coat color patterns are generated," Development, vol. 121, no. 10, pp. 3223-3232, 1995.

[8] N. Matsunaga, V. Virador, C. Santis et al., "In situ localization of agouti signal protein in murine skin using immunohistochemistry with an ASP-specific antibody," Biochemical and Biophysical Research Communications, vol. 270, no. 1, pp. 176-182, 2000.

[9] E. J. Michaud, S. J. Bultman, L. J. Stubbs, and R. P. Woychik, "The embryonic lethality of homozygous lethal yellow mice $(\mathrm{A}(\mathrm{y}) / \mathrm{A}(\mathrm{y}))$ is associated with the disruption of a novel RNAbinding protein," Genes and Development, vol. 7, no. 7 A, pp. 1203-1213, 1993.

[10] D. M. J. Duhl, M. E. Stevens, H. Vrieling et al., "Pleiotropic effects of the mouse lethal yellow $(\mathrm{A}(\mathrm{y}))$ mutation explained by deletion of a maternally expressed gene and the simultaneous production of agouti fusion RNAs," Development, vol. 120, no. 6, pp. 1695-1708, 1994.

[11] E. J. Michaud, S. J. Bultman, M. L. Klebig et al., "A molecular model for the genetic and phenotypic characteristics of the mouse lethal yellow $(\mathrm{A}(\mathrm{y}))$ mutation," Proceedings of the National Academy of Sciences of the United States of America, vol. 91, no. 7, pp. 2562-2566, 1994.

[12] M. L. Klebig, J. E. Wilkinson, J. G. Geisler, and R. P. Woychik, "Ectopic expression of the agouti gene in transgenic mice causes obesity, features of type II diabetes, and yellow fur," Proceedings of the National Academy of Sciences of the United States of America, vol. 92, no. 11, pp. 4728-4732, 1995.

[13] R. L. Mynatt, R. J. Miltenberger, M. L. Klebig et al., "Combined effects of insulin treatment and adipose tissuespecific agouti expression on the development of obesity," Proceedings of the National Academy of Sciences of the United States of America, vol. 94, no. 3, pp. 919-922, 1997.

[14] H. Y. Kwon, S. J. Bultman, C. Löffler et al., "Molecular structure and chromosomal mapping of the human homolog of the agouti gene," Proceedings of the National Academy of Sciences of the United States of America, vol. 91, no. 21, pp. 9760-9764, 1994.

[15] B. D. Wilson, M. M. Ollmann, L. Kang, M. Stoffel, G. I. Bell, and G. S. Barsh, "Structure and function of ASP, the human homolog of the mouse agouti gene," Human Molecular Genetics, vol. 4, no. 2, pp. 223-230, 1995.

[16] S. R. Smith, B. Gawronska-Kozak, L. Janderová et al., "Agouti expression in human adipose tissue: functional consequences and increased expression in type 2 diabetes," Diabetes, vol. 52, no. 12, pp. 2914-2922, 2003.

[17] B. Z. Xue, W. O. Wilkison, R. L. Mynatt, N. Moustaid, M. Goldman, and M. B. Zemel, "The agouti gene product stimulates pancreatic $\beta$-cell $\mathrm{Ca}^{2+}$ signaling and insulin release," Physiological Genomics, vol. 1999, no. 1, pp. 11-19, 1999.

[18] G. T. Kucera, D. M. Bortner, and M. P. Rosenberg, "Overexpression of an Agouti cDNA in the skin of transgenic mice recapitulates dominant coat color phenotypes of spontaneous mutants," Developmental Biology, vol. 173, no. 1, pp. 162-173, 1996.
[19] A. M. Ingalls, M. M. Dickie, and G. D. Snell, "Obese, a new mutation in the house mouse," The Journal of Heredity, vol. 41, no. 12, pp. 317-318, 1950.

[20] Y. Zhang, R. Proenca, M. Maffei, M. Barone, L. Leopold, and J. M. Friedman, "Positional cloning of the mouse obese gene and its human homologue," Nature, vol. 372, no. 6505, pp. 425-432, 1994.

[21] K. P. Hummel, M. M. Dickie, and D. L. Coleman, "Diabetes, a new mutation in the mouse," Science, vol. 153, no. 3740, pp. 1127-1128, 1966.

[22] H. Chen, O. Charlat, L. A. Tartaglia et al., "Evidence that the diabetes gene encodes the leptin receptor: identification of a mutation in the leptin receptor gene in $\mathrm{db} / \mathrm{db}$ mice," Cell, vol. 84, no. 3, pp. 491-495, 1996.

[23] G. H. Lee, R. Proenca, J. M. Montez et al., "Abnormal splicing of the leptin receptor in diabetic mice," Nature, vol. 379, no. 6566, pp. 632-635, 1996.

[24] L. Herberg and D. L. Coleman, "Laboratory animals exhibiting obesity and diabetes syndromes," Metabolism, vol. 26, no. 1, pp. 59-99, 1977.

[25] H. S. Jürgens, A. Schürmann, R. Kluge et al., "Hyperphagia, lower body temperature, and reduced running wheel activity precede development of morbid obesity in New Zealand obese mice," Physiological Genomics, vol. 25, no. 2, pp. 234241, 2006.

[26] W. Suzuki, S. Iizuka, M. Tabuchi et al., "A new mouse model of spontaneous diabetes derived from ddY strain," Experimental Animals, vol. 48, no. 3, pp. 181-189, 1999.

[27] I. Hirayama, Z. Yi, S. Izumi et al., "Genetic analysis of obese diabetes in the TSOD mouse," Diabetes, vol. 48, no. 5, pp. 1183-1191, 1999.

[28] S. Iizuka, W. Suzuki, M. Tabuchi et al., "Diabetic complications in a new animal model (TSOD mouse) of spontaneous NIDDM with obesity," Experimental Animals, vol. 54, no. 1, pp. 71-83, 2005.

[29] M. F. Allan, E. J. Eisen, and D. Pomp, “The M16 mouse: an outbred animal model of early onset polygenic obesity and diabesity," Obesity Research, vol. 12, no. 9, pp. 1397-1407, 2004.

[30] M. Nakamura and K. Yamada, "Studies on a diabetic (KK) strain of the mouse," Diabetologia, vol. 3, no. 2, pp. 212-221, 1967.

[31] M. Igel, B. A. Taylor, S. J. Phillips, W. Becker, L. Herberg, and H. G. Joost, "Hyperleptinemia and leptin receptor variant Asp600Asn in the obese, hyperinsulinemic KK mouse strain," Journal of Molecular Endocrinology, vol. 21, no. 3, pp. 337345, 1998.

[32] T. Shike, S. Hirose, M. Kobayashi, K. Funabiki, T. Shirai, and Y. Tomino, "Susceptibility and negative epistatic loci contributing to type 2 diabetes and related phenotypes in a KK/Ta mouse model," Diabetes, vol. 50, no. 8, pp. 1943-1948, 2001.

[33] H. Ikeda, "KK mouse," Diabetes Research and Clinical Practice, vol. 24, supplement, pp. S313-S316, 1994.

[34] M. Okazaki, Y. Saito, Y. Udaka et al., "Diabetic nephropathy in KK and KK-A mice," Experimental Animals, vol. 51, no. 2, pp. 191-196, 2002.

[35] L. M. Zucker and T. F. Zucker, "Fatty, a new mutation in the rat,” Journal of Heredity, vol. 52, no. 6, pp. 275-278, 1961.

[36] L. M. Zucker and H. N. Antoniades, "Insulin and obesity in the Zucker genetically obese rat "fatty"', Endocrinology, vol. 90, no. 5, pp. 1320-1330, 1972.

[37] G. A. Bray, "The Zucker fatty rat: a review," Federation Proceedings, vol. 36, no. 2, pp. 148-153, 1977. 
[38] Y. Ogawa, H. Masuzaki, N. Isse et al., "Molecular cloning of rat obese cDNA and augmented gene expression in genetically obese Zucker fatty (fa/fa) rats," Journal of Clinical Investigation, vol. 96, no. 3, pp. 1647-1652, 1995.

[39] J. E. Friedman, J. E. De Vente, R. G. Peterson, and G. L. Dohm, "Altered expression of muscle glucose transporter GLUT-4 in diabetic fatty Zucker rats (ZDF/Drt-fa)," American Journal of Physiology, vol. 261, no. 6, pp. E782-E788, 1991.

[40] H. Ikeda, A. Shino, T. Matsuo, H. Iwatsuka, and Z. Suzuoki, "A new genetically obese-hyperglycemic rat (Wistar fatty)," Diabetes, vol. 30, no. 12, pp. 1045-1050, 1981.

[41] H. Matsui, M. Suzuki, R. Tsukuda, K. Iida, M. Miyasaka, and H. Ikeda, "Expression of ICAM-1 on glomeruli is associated with progression of diabetic nephropathy in a genetically obese diabetic rat, Wistar fatty," Diabetes Research and Clinical Practice, vol. 32, no. 1-2, pp. 1-9, 1996.

[42] G. Imai, T. Satoh, T. Kumai et al., "Hypertension accelerates diabetic nephropathy in Wistar fatty rats, a model of type 2 diabetes mellitus, via mitogen-activated protein kinase cascades and transforming growth factor- $\beta 1$," Hypertension Research, vol. 26, no. 4, pp. 339-347, 2003.

[43] K. Imai, N. Kudo, M. Koyama, and Y. Kawashima, "Effects of dehydroepiandrosterone on oleic acid accumulation in rat liver," Biochemical Pharmacology, vol. 65, no. 10, pp. 15831591, 2003.

[44] L. N. Berti-Mattera, J. Lowery, S. F. Day, R. G. Peterson, and J. Eichberg, "Alteration of phosphoinositide metabolism, protein phosphorylation, and carbohydrate levels in sciatic nerve from Wistar fatty diabetic rats," Diabetes, vol. 38, no. 3, pp. 373-378, 1989.

[45] K. Kawano, T. Hirashima, S. Mori, Y. Saitoh, M. Kurosumi, and T. Natori, "Spontaneous long-term hyperglycemic rat with diabetic complications: Otsuka Long-Evans Tokushima Fatty (OLETF) strain," Diabetes, vol. 41, no. 11, pp. 14221428, 1992.

[46] K. Kawano, T. Hirashima, S. Mori, and T. Natori, "OLETF (Otsuka Long-Evans Tokushima fatty) rat: a new NIDDM rat strain," Diabetes Research and Clinical Practice, vol. 24, pp. S317-S320, 1994.

[47] D. Jia, M. Taguchi, and M. Otsuki, "Synthetic protease inhibitor camostat prevents and reverses dyslipidemia, insulin secretory defects, and histological abnormalities of the pancreas in genetically obese and diabetic rats," Metabolism, vol. 54, no. 5, pp. 619-627, 2005.

[48] D. B. West, C. N. Boozer, D. L. Moody, and R. L. Atkinson, "Dietary obesity in nine inbred mouse strains," American Journal of Physiology, vol. 262, no. 6, pp. R1025-R1032, 1992.

[49] S. Collins, T. L. Martin, R. S. Surwit, and J. Robidoux, "Genetic vulnerability to diet-induced obesity in the C57BL/6J mouse: physiological and molecular characteristics," Physiology and Behavior, vol. 81, no. 2, pp. 243-248, 2004.

[50] K. Srinivasan and P. Ramarao, "Animal models in type 2 diabetes research: an overview," Indian Journal of Medical Research, vol. 125, no. 3, pp. 451-472, 2007.

[51] M. Watanabe, S. M. Houten, C. Mataki et al., "Bile acids induce energy expenditure by promoting intracellular thyroid hormone activation," Nature, vol. 439, no. 7075, pp. 484-489, 2006.

[52] C. Thomas, A. Gioiello, L. Noriega et al., "TGR5mediated bile acid sensing controls glucose homeostasis," Cell Metabolism, vol. 10, no. 3, pp. 167-177, 2009.
[53] A. De Santis, A. F. Attili, S. G. Corradini et al., "Gallstones and diabetes: a case-control study in a free-living population sample," Hepatology, vol. 25, no. 4, pp. 787-790, 1997.

[54] Y. Zhang, K. Guo, R. E. LeBlanc, D. Loh, G. J. Schwartz, and $\mathrm{Y} . \mathrm{H}$. Yu, "Increasing dietary leucine intake reduces diet-induced obesity and improves glucose and cholesterol metabolism in mice via multimechanisms," Diabetes, vol. 56, no. 6, pp. 1647-1654, 2007.

[55] Y. Noguchi, N. Nishikata, N. Shikata et al., "Ketogenic essential amino acids modulate lipid synthetic pathways and prevent hepatic steatosis in mice," PLoS One, vol. 5, no. 8, Article ID e12057, 2010.

[56] S. B. Solerte, C. Gazzaruso, N. Schifino et al., "Metabolic effects of orally administered amino acid mixture in elderly subjects with poorly controlled type 2 diabetes mellitus," American Journal of Cardiology, vol. 93, no. 8, pp. 23A-29A, 2004.

[57] E. Eizirik, W. J. Murphy, and S. J. O’Brien, "Molecular dating and biogeography of the early placental mammal radiation," Journal of Heredity, vol. 92, no. 2, pp. 212-219, 2001.

[58] S. L. Page and M. Goodman, "Catarrhine phylogeny: noncoding DNA evidence for a diphyletic origin of the mangabeys and for a human-chimpanzee clade," Molecular Phylogenetics and Evolution, vol. 18, no. 1, pp. 14-25, 2001.

[59] B. C. Hansen and N. L. Bodkin, "Heterogeneity of insulin responses: phases leading to type 2 (non-insulin-dependent) diabetes mellitus in the rhesus monkey," Diabetologia, vol. 29, no. 10, pp. 713-719, 1986.

[60] N. L. Bodkin, J. S. Hannah, H. K. Ortmeyer, and B. C. Hansen, "Central obesity in rhesus monkeys: association with hyperinsulinemia, insulin resistance and hypertriglyceridemia?" International Journal of Obesity, vol. 17, no. 1, pp. 53-61, 1993.

[61] N. L. Bodkin, H. K. Ortmeyer, and B. C. Hansen, "Diversity of insulin resistance in monkeys with normal glucose tolerance," Obesity Research, vol. 1, no. 5, pp. 364-370, 1993.

[62] J. W. Kemnitz, "Obesity in macaques: spontaneous and induced," Advances in Veterinary Science and Comparative Medicine, vol. 28, pp. 81-114, 1984.

[63] B. C. Hansen and N. L. Bodkin, "Primary prevention of diabetes mellitus by prevention of obesity in monkeys," Diabetes, vol. 42, no. 12, pp. 1809-1814, 1993.

[64] B. C. Hansen, H. K. Ortmeyer, and N. L. Bodkin, "Prevention of obesity in middle-aged monkeys: food intake during body weight clamp," Obesity Research, vol. 3, supplement 2, pp. 199s-204s, 1995.

[65] J. Altmann, D. Schoeller, S. A. Altmann, P. Muruthi, and R. M. Sapolsky, "Body size and fatness of free-living baboons reflect food availability and activity levels," American Journal of Primatology, vol. 30, pp. 149-161, 1993.

[66] W. A. Banks, J. Altmann, R. M. Sapolsky, J. E. PhillipsConroy, and J. E. Morley, "Serum leptin levels as a marker for a syndrome X-like condition in wild baboons," Journal of Clinical Endocrinology and Metabolism, vol. 88, no. 3, pp. 1234-1240, 2003.

[67] W. A. Banks, J. E. Phillips-Conroy, C. J. Jolly, and J. E. Morley, "Serum leptin levels in wild and captive populations of baboons (papio): implications for the ancestral role of leptin," Journal of Clinical Endocrinology and Metabolism, vol. 86, no. 9, pp. 4315-4320, 2001.

[68] S. M. Schwartz, J. W. Kemnitz, and C. F. Howard Jr., "Obesity in free-ranging rhesus macaques," International Journal of Obesity, vol. 17, no. 1, pp. 1-9, 1993. 
[69] T. Takahashi, A. Higashino, K. Takagi et al., "Characterization of obesity in Japanese monkeys (Macaca fuscata) in a pedigreed colony," Journal of Medical Primatology, vol. 35, no. 1, pp. 30-37, 2006.

[70] N. Matsuoka, Y. Ogawa, K. Hosoda et al., "Human leptin receptor gene in obese Japanese subjects: evidence against either obesity-causing mutations or association of sequence variants with obesity," Diabetologia, vol. 40, no. 10, pp. 1204 1210, 1997.

[71] K. Clément, C. Vaisse, N. Lahlou et al., "A mutation in the human leptin receptor gene causes obesity and pituitary dysfunction," Nature, vol. 392, no. 6674, pp. 398-401, 1998.

[72] V. Rolland, "Leptin receptor gene in a large cohort of massively obese subjects: no indication of the fa/fa rat mutation. Detection of an intronic variant with no association with obesity," Obesity Research, vol. 6, no. 2, pp. 122-127, 1998.

[73] R. S. Surwit, M. F. Seldin, C. M. Kuhn, C. Cochrane, and M. N. Feinglos, "Control of expression of insulin resistance and hyperglycemia by different genetic factors in diabetic C57BL/6J mice," Diabetes, vol. 40, no. 1, pp. 82-87, 1991.

[74] J. Speakman, C. Hambly, S. Mitchell, and E. Król, "Animal models of obesity," Obesity Reviews, vol. 8, no. 1, pp. 55-61, 2007.

[75] S. M. Clee and A. D. Attie, "The genetic landscape of type 2 diabetes in mice," Endocrine Reviews, vol. 28, no. 1, pp. 48-83, 2007.

[76] E. E. Calle and R. Kaaks, "Overweight, obesity and cancer: epidemiological evidence and proposed mechanisms," Nature Reviews Cancer, vol. 4, no. 8, pp. 579-591, 2004.

[77] E. E. Calle, C. Rodriguez, E. J. Jacobs et al., "The American Cancer Society Cancer Prevention Study II Nutrition Cohort: rationale, study design, and baseline characteristics," Cancer, vol. 94, no. 9, pp. 2490-2501, 2002.

[78] E. E. Calle, C. Rodriguez, E. J. Jacobs et al., "The American Cancer Society Cancer Prevention Study II Nutrition Cohort: rationale, study design, and baseline characteristics," Cancer, vol. 94, no. 9, pp. 2490-2501, 2002.

[79] E. E. Calle, C. Rodriguez, K. Walker-Thurmond, and M. J. Thun, "Overweight, obesity, and mortality from cancer in a prospectively studied cohort of U.S. Adults," The New England Journal of Medicine, vol. 348, no. 17, pp. 1625-1638, 2003.

[80] E. E. Calle, M. J. Thun, J. M. Petrelli, C. Rodriguez, and C. W. Heath Jr., "Body-mass index and mortality in a prospective cohort of U.S. adults," The New England Journal of Medicine, vol. 341, no. 15, pp. 1097-1105, 1999.

[81] E. J. Park, J. H. Lee, G. Y. Yu et al., "Dietary and genetic obesity promote liver inflammation and tumorigenesis by enhancing IL-6 and TNF expression," Cell, vol. 140, no. 2, pp. 197-208, 2010.

[82] R. J. Shaw, K. A. Lamia, D. Vasquez et al., "Medicine: the kinase LKB1 mediates glucose homeostasis in liver and therapeutic effects of metformin," Science, vol. 310, no. 5754, pp. 1642-1646, 2005.

[83] R. J. O. Dowling, M. Zakikhani, I. G. Fantus, M. Pollak, and N. Sonenberg, "Metformin inhibits mammalian target of rapamycin-dependent translation initiation in breast cancer cells," Cancer Research, vol. 67, no. 22, pp. 10804-10812, 2007.

[84] D. B. Shackelford and R. J. Shaw, "The LKB1-AMPK pathway: metabolism and growth control in tumour suppression," Nature Reviews Cancer, vol. 9, no. 8, pp. 563-575, 2009.
[85] A. Kalender, A. Selvaraj, S. Y. Kim et al., "Metformin, independent of AMPK, inhibits mTORC1 in a rag GTPasedependent manner," Cell Metabolism, vol. 11, no. 5, pp. 390$401,2010$.

[86] R. Saeedi, H. L. Parsons, R. B. Wambolt et al., "Metabolic actions of metformin in the heart can occur by AMPKindependent mechanisms," American Journal of Physiology, vol. 294, no. 6, pp. H2497-H2506, 2008.

[87] J. M. Dhahbi, P. L. Mote, G. M. Fahy, and S. R. Spindler, "Identification of potential caloric restriction mimetics by microarray profiling," Physiological Genomics, vol. 23, no. 3, pp. 343-350, 2005.

[88] B. J. Merry, "Molecular mechanisms linking calorie restriction and longevity," International Journal of Biochemistry and Cell Biology, vol. 34, no. 11, pp. 1340-1354, 2002.

[89] J. M. Dhahbi, H. J. Kim, P. L. Mote, R. J. Beaver, and S. R. Spindler, "Temporal linkage between the phenotypic and genomic responses to caloric restriction," Proceedings of the National Academy of Sciences of the United States of America, vol. 101, no. 15, pp. 5524-5529, 2004.

[90] C. Algire, L. Amrein, M. Zakikhani, L. Panasci, and M. Pollak, "Metformin blocks the stimulative effect of a high-energy diet on colon carcinoma growth in vivo and is associated with reduced expression of fatty acid synthase," Endocrine-Related Cancer, vol. 17, no. 2, pp. 351-360, 2010.

[91] K. N. Phoenix, F. Vumbaca, M. M. Fox, R. Evans, and K. P. Claffey, "Dietary energy availability affects primary and metastatic breast cancer and metformin efficacy," Breast Cancer Research and Treatment, vol. 123, no. 2, pp. 333-344, 2010.

[92] A. M. Ribeiro, S. Andrade, F. Pinho et al., "Prostate cancer cell proliferation and angiogenesis in different obese mice models," International Journal of Experimental Pathology, vol. 91, no. 4, pp. 374-386, 2010.

[93] R. R. Gonzalez, S. Cherfils, M. Escobar et al., "Leptin signaling promotes the growth of mammary tumors and increases the expression of vascular endothelial growth factor (VEGF) and its receptor type two (VEGF-R2)," Journal of Biological Chemistry, vol. 281, no. 36, pp. 26320-26328, 2006.

[94] R. Rene Gonzalez, A. Watters, Y. Xu et al., "Leptin-signaling inhibition results in efficient anti-tumor activity in estrogen receptor positive or negative breast cancer," Breast Cancer Research, vol. 11, no. 3, p. R36, 2009.

[95] D. Sharma, N. K. Saxena, P. M. Vertino, and F. A. Anania, "Leptin promotes the proliferative response and invasiveness in human endometrial cancer cells by activating multiple signal-transduction pathways," Endocrine-Related Cancer, vol. 13, no. 2, pp. 629-640, 2006.

[96] M. Bartucci, S. Svensson, L. Ricci-Vitiani et al., "Obesity hormone leptin induces growth and interferes with the cytotoxic effects of 5-fluorouracil in colorectal tumor stem cells," Endocrine-Related Cancer, vol. 17, no. 3, pp. 823-833, 2010.

[97] J. C. Hendricks, L. R. Kline, R. J. Kovalski, J. A. O’Brien, A. R. Morrison, and A. I. Pack, "The English bulldog: a natural model of sleep-disordered breathing," Journal of Applied Physiology, vol. 63, no. 4, pp. 1344-1350, 1987.

[98] R. P. Lonergan, J. C. Ware, R. L. Atkinson, W. C. Winter, and P. M. Suratt, "Sleep apnea in obese miniature pigs," Journal of Applied Physiology, vol. 84, no. 2, pp. 531-536, 1998.

[99] S. A. Tuck, J. C. Dort, M. E. Olson, and J. E. Remmers, "Monitoring respiratory function and sleep in the obese 
Vietnamese pot-bellied pig," Journal of Applied Physiology, vol. 87, no. 1, pp. 444-451, 1999.

[100] E. van Lunteren, "Effects of genetic obesity on rat upper airway muscle and diaphragm contractile properties," European Respiratory Journal, vol. 9, no. 10, pp. 2139-2144, 1996.

[101] M. Radulovacki, S. Trbovic, and D. W. Carley, "Hypotension reduces sleep apneas in Zucker lean and Zucker obese rats," Sleep, vol. 19, no. 10, pp. 767-773, 1996.

[102] D. Megirian, J. Dmochowski, and G. A. Farkas, "Mechanism controlling sleep organization of the obese Zucker rats," Journal of Applied Physiology, vol. 84, no. 1, pp. 253-256, 1998.

[103] M. J. Brennick, S. Pickup, J. R. Cater, and S. T. Kuna, "Phasic respiratory pharyngeal mechanics by magnetic resonance imaging in lean and obese Zucker rats," American Journal of Respiratory and Critical Care Medicine, vol. 173, no. 9, pp. 1031-1037, 2006.

[104] H. Nakano, U. J. Magalang, S. D. Lee, J. A. Krasney, and G. A. Farkas, "Serotonergic modulation of ventilation and upper airway stability in obese Zucker rats," American Journal of Respiratory and Critical Care Medicine, vol. 163, no. 5, pp. 1191-1197, 2001.

[105] L. L. Peters, R. F. Robledo, C. J. Bult, G. A. Churchill, B. J. Paigen, and K. L. Svenson, "The mouse as a model for human biology: a resource guide for complex trait analysis," Nature Reviews Genetics, vol. 8, no. 1, pp. 58-69, 2007.

[106] Y. Tagaito, V. Y. Polotsky, M. J. Campen et al., "A model of sleep-disordered breathing in the C57BL/6J mouse," Journal of Applied Physiology, vol. 91, no. 6, pp. 2758-2766, 2001.

[107] M. J. Brennick, A. I. Pack, K. Ko et al., "Altered upper airway and soft tissue structures in the New Zealand obese mouse," American Journal of Respiratory and Critical Care Medicine, vol. 179, no. 2, pp. 158-169, 2009.

[108] B. K. Smith, D. B. West, and D. A. York, "Carbohydrate versus fat intake: differing patterns of macronutrient selection in two inbred mouse strains," American Journal of Physiology, vol. 272, no. 1, pp. R357-R362, 1997.

[109] B. K. Smith, L. A. Kelly, R. Piña, D. A. York, and G. A. Bray, "Preferential fat intake increases adiposity but not body weight in Sprague-Dawley rats," Appetite, vol. 31, no. 2, pp. 127-139, 1998.

[110] B. K. Smith, P. K. Andrews, and D. B. West, "Macronutrient diet selection in thirteen mouse strains," American Journal of Physiology, vol. 278, no. 4, pp. R797-R805, 2000.

[111] M. W. Schwartz, S. C. Woods, D. Porte, R. J. Seeley, and D. G. Baskin, "Central nervous system control of food intake," Nature, vol. 404, no. 6778, pp. 661-671, 2000.

[112] J. N. Crawley, "The role of galanin in feeding behavior," Neuropeptides, vol. 33, no. 5, pp. 369-375, 1999.

[113] M. Odorizzi, B. Fernette, E. Angel, C. Burlet, P. Tankosic, and A. Burlet, "Galanin receptor antagonists decrease fat preference in Brattleboro rat," Neuropharmacology, vol. 42, no. 1, pp. 134-141, 2002.

[114] B. K. Smith, D. A. York, and G. A. Bray, "Chronic cerebroventricular galanin does not induce sustained hyperphagia or obesity," Peptides, vol. 15, no. 7, pp. 1267-1272, 1994.

[115] B. K. Smith, H. R. Berthoud, D. A. York, and G. A. Bray, "Differential effects of baseline macronutrient preferences on macronutrient selection after galanin, NPY, and an overnight fast," Peptides, vol. 18, no. 2, pp. 207-211, 1997.

[116] M. Jhanwar-Uniyal, B. Beck, Y. S. Jhanwar, C. Burlet, and S. F. Leibowitz, "Neuropeptide Y projection from arcuate nucleus to parvocellular division of paraventricular nucleus: specificfd relation to the ingestion of carbohydrate," Brain Research, vol. 631, no. 1, pp. 97-106, 1993.

[117] E. Carmina and R. A. Lobo, "Polycystic ovary syndrome (PCOS): arguably the most common endocrinopathy is associated with significant morbidity in women," Journal of Clinical Endocrinology and Metabolism, vol. 84, no. 6, pp. 1897-1899, 1999.

[118] D. Glintborg and M. Andersen, "An update on the pathogenesis, inflammation, and metabolism in hirsutism and polycystic ovary syndrome," Gynecological Endocrinology, vol. 26, no. 4, pp. 281-296, 2010.

[119] M. Rebuffe-Scrive, R. Surwit, M. Feinglos, C. Kuhn, and J. Rodin, "Regional fat distribution and metabolism in a new mouse model (C57BL/6J) of non-insulin-dependent diabetes mellitus," Metabolism, vol. 42, no. 11, pp. 1405-1409, 1993.

[120] D. L. Coleman and K. P. Hummel, "The influence of genetic background on the expression of the obese $(\mathrm{Ob})$ gene in the mouse," Diabetologia, vol. 9, no. 4, pp. 287-293, 1973.

[121] A. A. Toye, J. D. Lippiat, P. Proks et al., "A genetic and physiological study of impaired glucose homeostasis control in C57BL/6J mice," Diabetologia, vol. 48, no. 4, pp. 675-686, 2005.

[122] D. L. Coleman, "The influence of genetic background on the expression of mutations at the diabetes $(\mathrm{db})$ locus in the mouse VI: hepatic malic enzyme activity is associated with diabetes severity," Metabolism, vol. 41, no. 10, pp. 1134-1136, 1992.

[123] K. Almind and C. R. Kahn, "Genetic determinants of energy expenditure and insulin resistance in diet-induced obesity in mice," Diabetes, vol. 53, no. 12, pp. 3274-3285, 2004.

[124] E. H. Leiter, D. L. Coleman, A. B. Eisenstein, and I. Strack, "A new mutation (db3J) at the diabetes locus in strain 129/J mice. I. Physiological and histological characterization," Diabetologia, vol. 19, pp. 58-65, 1980.

[125] J. B. Flowers, A. T. Oler, S. T. Nadler et al., "Abdominal obesity in BTBR male mice is associated with peripheral but not hepatic insulin resistance," American Journal of Physiology, vol. 292, no. 3, pp. E936-E945, 2007.

[126] S. M. Clee, S. T. Nadler, and A. D. Attie, "Genetic and genomic studies of the BTBR ob/ob mouse model of type 2 diabetes," American Journal of Therapeutics, vol. 12, no. 6, pp. 491-498, 2005.

[127] R. S. Surwit, C. M. Kuhn, C. Cochrane, J. A. McCubbin, and M. N. Feinglos, "Diet-induced type II diabetes in C57BL/6J mice," Diabetes, vol. 37, no. 9, pp. 1163-1167, 1988.

[128] R. S. Surwit, M. N. Feinglos, J. Rodin et al., "Differential effects of fat and sucrose on the development of obesity and diabetes in C57BL/6J and A/J mice," Metabolism, vol. 44, no. 5, pp. 645-651, 1995.

[129] J. Qiu, S. Ogus, K. Mounzih, A. Ewart-Toland, and F. F. Chehab, "Leptin-deficient mice backcrossed to the BALB/cJ genetic background have reduced adiposity, enhanced fertility, normal body temperature, and severe diabetes," Endocrinology, vol. 142, no. 8, pp. 3421-3425, 2001.

[130] B. York, K. Lei, and D. B. West, "Sensitivity to dietary obesity linked to a locus on chromosome 15 in a CAST/Ei $\times$ C57BL/6J F intercross," Mammalian Genome, vol. 7, no. 9, pp. 677-681, 1996.

[131] S. Chua, S. M. Liu, Q. Li, L. Yang, V. Thassanapaff, and P. Fisher, "Differential beta cell responses to hyperglycaemia and insulin resistance in two novel congenic strains of diabetes (FVB-Lepr) and obese (DBA-Lep) mice," Diabetologia, vol. 45, no. 7, pp. 976-990, 2002. 
[132] J. H. Kim, A. Sen, C. S. Avery et al., "Genetic analysis of a new mouse model for non-insulin-dependent diabetes," Genomics, vol. 74, no. 3, pp. 273-286, 2001.

[133] H. Ueda, H. Ikegami, E. Yamato et al., "The NSY mouse: a new animal model of spontaneous NIDDM with moderate obesity," Diabetologia, vol. 38, no. 5, pp. 503-508, 1995.

[134] C. E. Mathews and E. H. Leiter, "Resistance of ALR/Lt islets to free radical-mediated diabetogenic stress is inherited as a dominant trait," Diabetes, vol. 48, no. 11, pp. 2189-2196, 1999.

[135] F. Sekiguchi, K. Ishibashi, Y. Kawamoto, and T. Ino, "Diabetic peculiarity of the ALS-Ay and ALR-Ay strains," Jikken Dobutsu, vol. 40, no. 3, pp. 323-329, 1991.

[136] T. H. Ehrich, J. P. Kenney, T. T. Vaughn, L. S. Pletscher, and J. M. Cheverud, "Diet, obesity, and hyperglycemia in LG/J and SM/J mice," Obesity Research, vol. 11, no. 11, pp. 1400-1410, 2003.

[137] M. Yoshioka, T. Kayo, T. Ikeda, and A. Koizumi, "A novel locus, Mody4, distal to D7Mit189 on chromosome 7 determines early-onset NIDDM in nonobese C57BL/6 (Akita) mutant mice," Diabetes, vol. 46, no. 5, pp. 887-894, 1997. 


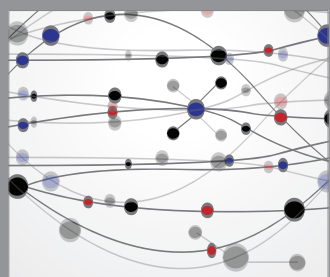

The Scientific World Journal
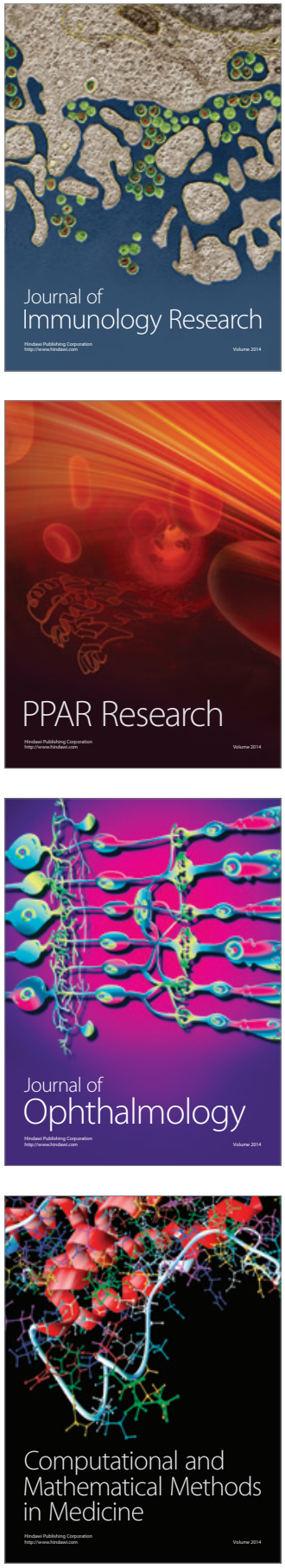

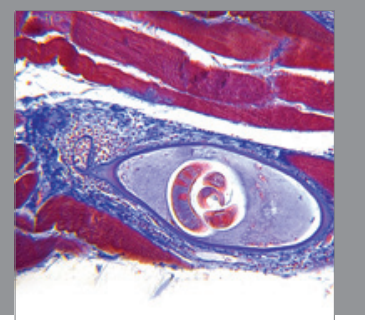

Gastroenterology

Research and Practice
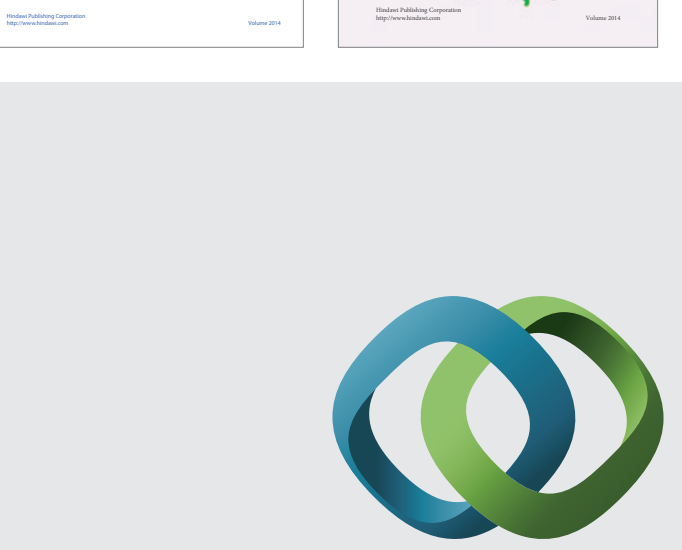

\section{Hindawi}

Submit your manuscripts at

http://www.hindawi.com
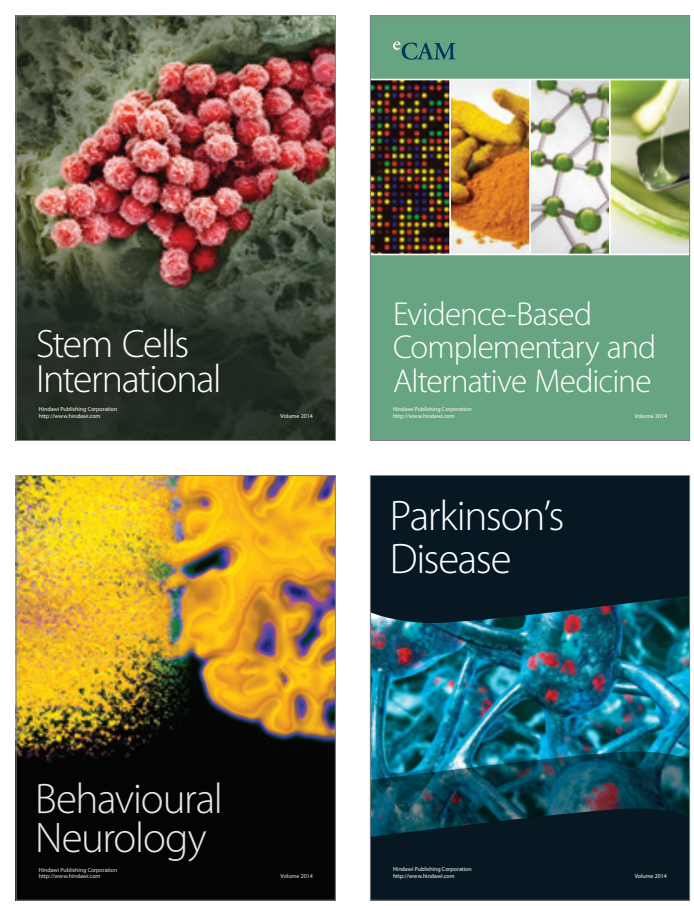

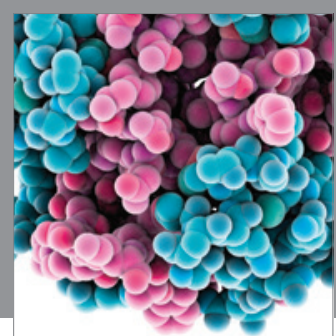

Journal of
Diabetes Research

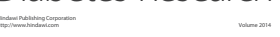

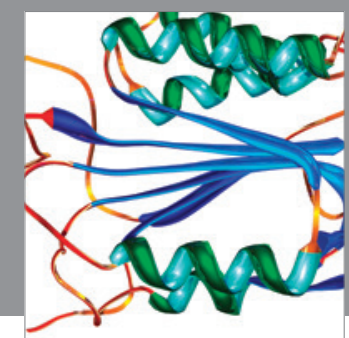

Disease Markers
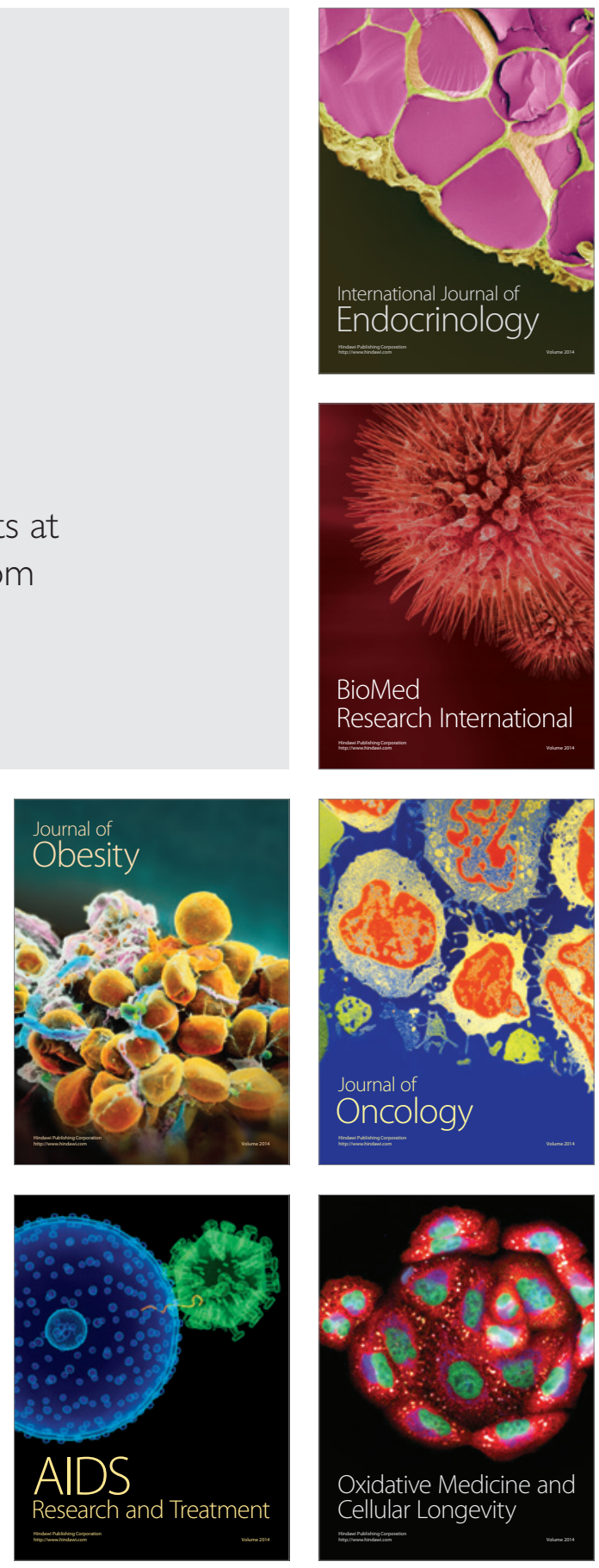